\title{
The Influence of Ruggedness Reviews 3- Dimensional Photo Carving Media Based on 3- Axis CNC Router
}

\author{
Noor Yulita Dwi Setyaningsih ${ }^{1}$, Khan Annudin ${ }^{2}$, Solekhan ${ }^{3}$ \\ 1, 2, 3 Department of Electrical Engineering, Universitas Muria Kudus, Indonesia \\ Email: ${ }^{1}$ noor.yulita@umk.ac.id, ${ }^{2}$ khan.annudin@umk.ac.id, ${ }^{3}$ solekhan@umk.ac.id
}

\begin{abstract}
Today's face relief is very popular with people, both for gifts at special events or for mementos. Not everyone is able and able to produce or create relief carving 3-dimensional photos properly, so research on 3D photo carving using a CNC machine was made. CNC machine is a tool used to engrave and produce 3-dimensional photo engraving automatically. This research uses the Aspire application to create a G-Code type image. Next, connect the Arduino which in this case is used as the control device to enter the G-code obtained using the GRBL Control application. The gap in media reviews affects the time it takes in the manufacturing process, wherewith the same image design it is found that the greater the stretch of the reviews, the faster the time needed but the carving results are lined and rough. Likewise, the opposite condition, the smaller the gap in the review, the longer it takes, and the results obtained are smoother. So that in the future it can make a combination of choices from the stretch of reviews for engraved images.
\end{abstract}

Keywords - estrangement reviews, engraving, 3-dimensional photos, CNC routers, wood media

\section{INTRODUCTION (HEADING 1)}

At this time, there are a lot of products that are given to someone to be a surprise or a keepsake. One that is in great demand is facial relief. However, not all have the expertise to design a person's facial relief, be it on paper, wood, acrylic, or other image media. With the rapid development of technology, problems that arise can be resolved. By utilizing a machine, to be able to draw or carve faces to replace humans. This machine can automatically produce facial relief carvings according to the desired design.

A machine that is controlled using a computer by utilizing command data in the form of numeric codes, letters, and symbols which is usually referred to as a numeric language under ISO standards has been very widely used. This machine is more commonly known as a CNC (Computer Numerical Control) machine [1]-[5]. This CNC machine is very flexible and can be adjusted according to need, suitable for mass production, so many people use this machine for business [2], [5]-[8]. This is because the technology system between computers and mechanics is more synchronous. There are many types of CNC machines, one of which is the Router type [2], [7], [9]-[11]. This type is usually used to engrave and engrave objects. CNC machines have two or more directions of motion, namely axis motion and circular motion [12]-[18]. The axis movements include straight movements, which are generally found on the X, Y, Z axes [1], [10], [13], [17].

CNC Router Machine is a combination of CNC (Computer Numerical Control) technology and router, cutter which is capable of cutting wood sheet shapes or other soft materials that have complicated shapes and require precision in feeding [19]-[25]. This combination forms a computercontrolled cutting machine using a router machine to cut various materials such as wood, composite, aluminum, mild steel, plastic, acrylic glass, and foam by adopting CNC technology [26]. The working system of CNC technology is more synchronous between computer and mechanics when compared to similar machine tools so that this $\mathrm{CNC}$ machine is more precise, more precise, and more flexible. By inserting a layout that has been converted into G-Code from a computer/laptop into the device, the tool will work itself automatically, forming according to the commands entered into the tool [22], [24], [27]-[30]. It is hoped that the design of this tool can help students so that student activities in making PCB layouts and by making a microcontroller-based CNC machine can help the development of small industries in the field of wood carving. Because it only requires operator skills in tool operation and design making, it can be efficient, easy, and fast [27]. There is also the use of a CNC milling machine which is a development of conventional milling machines. At first, the $\mathrm{CNC}$ milling machine consisted of 3 axes, namely XYZ, which could make $3 \mathrm{D}$ products. With the development of technology, the axis of the CNC milling machine has reached 5 axes so that it can make products with high complexity [31].

In previous research, CNC Router machines used for engraving have also been carried out. The design focus used is traditional motifs for the furniture industry in Jepara. Application software using 3D studio Max [32]. Besides being used for engraving, CNC routers are also used for making balls crews. The software used in making the balls crew is AutoCAD and Mastercam. Both of these applications function to produce the NC Code data for the desired design image [10]. From the two previous studies, the software used is relatively difficult to operate, and not everyone has the skills to be able to operate the software. So that in this study utilizing the Aspire software to use because it is simpler and easier to operate. 
In the electronic world, this CNC Router machine is also used for PCB (Printed Circuit Board) drilling machines. This research functioned to minimize drilling errors that were done manually. The $\mathrm{CNC}$ working system used has automatic movement on the $\mathrm{X}, \mathrm{Y}$, and $\mathrm{Z}$ axes [11]. Besides being used by PCB drilling machines, this CNC machine is also used for PCB layout making. The results obtained from the use of CNC machines are time and energy efficiency in making PCB layouts. However, there are obstacles faced, namely the drill bit is rarely sold in the market and the work is not yet done for Double Layer PC [12].

So that in this study the development of the use of a CNC Router machine to carve faces in 3 dimensions with wood carving media, and the depth of the carving used is $5 \mathrm{~mm}$, with dimensions of measuring media length $90 \mathrm{~mm}$, width $90 \mathrm{~mm}$, thickness $17 \mathrm{~mm}$. In this study, we will make a comparison of the influence of the size of the stretch of review on the carving results obtained.

\section{RESEARCH METHOD}

The methodology in this research consists of 5 stages, namely, literature study, mechanical design, hardware design, software design, prototype design.

At this mechanical design stage, what is done is to make a skeleton design from the 3 mechanical axes used, namely the frame for the $\mathrm{X}$-axis, the $\mathrm{Y}$-axis, and the $\mathrm{Z}$-axis. The $\mathrm{X}$ axis is used for back and forth movement, the Y-axis for movement left and right. and the axis. $\mathrm{Z}$ is used for movement up and down. The framework material used is aluminum. For $\mathrm{X}$-axis frames, the size is $2 \times 2 \mathrm{~cm}$ with a length of $50 \mathrm{~cm}$. While the rail wheel uses a bearing size of $8 \mathrm{~mm}$ with type 608 , on the $\mathrm{X}$-axis it has 2 poles, namely the right pole and the left pole, each pole has a height of $40 \mathrm{~cm}$, each pole uses 4 bearings ( 2 top and 2 pieces the bottom) as the wheels. For the $\mathrm{Y}$-axis here it also uses $2 \times 2 \mathrm{~cm}$ aluminum profiles as the frame as well as the rails, for the rail wheels, 4 bearings still use 608 pieces. The $\mathrm{Y}$-axis consists of two aluminum profile bars (one profile aluminum bar for the top rail and one profile aluminum bar for the bottom rail). The two aluminum profile bars are $50 \mathrm{~cm}$ long with a top and bottom distance of $6.5 \mathrm{~cm}$. While the distance from the bottom profile aluminum rod to the base of the $\mathrm{X}$-axis is $15.8 \mathrm{~cm}$. And the last is the $\mathrm{Z}$-axis where the $\mathrm{Z}$-axis is here as the tool, the movement of the $\mathrm{Z}$ axis is up and down which is driven by a stepper motor. Where the length of the Z-axis rail is $25 \mathrm{~cm}$, the distance between the right rail and the left rail is $6 \mathrm{~cm}$, and the distance between the rail and the $\mathrm{X}$-axis base is $6.3 \mathrm{~cm}$. The form of the $X$-axis mechanical design can be seen in Figure 1 (a), the $\mathrm{Y}$-axis design in Figure 1 (b), and the $\mathrm{Z}$-axis design in Figure 1 (c).

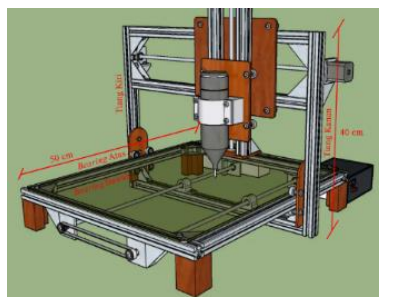

(a) $\mathrm{X}$-axis

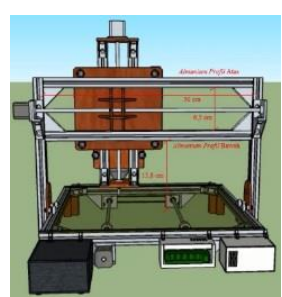

(b) $\mathrm{Y}$-axis

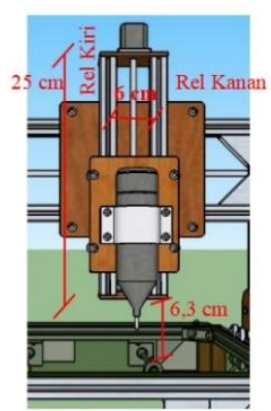

(c) Z-axis

Fig. 1. (a) $\mathrm{X}$ axis, (b) $\mathrm{Y}$ axis, (c) $\mathrm{Z}$ axis

The hardware design used in this study is shown in Figure 2.

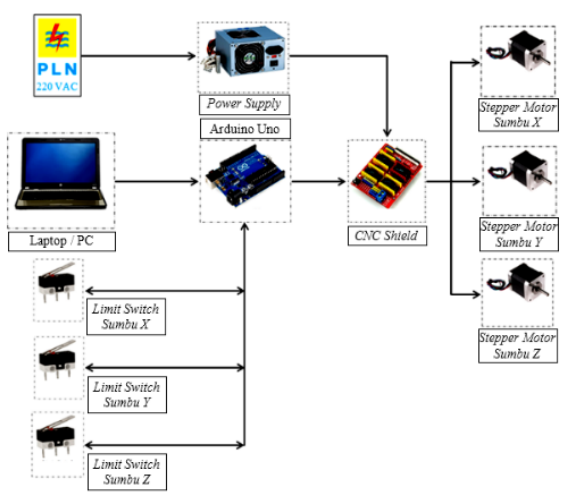

Fig. 2. Hardware Design

The main component of the tool made is the Arduino Uno which functions to read the G code uploaded from a laptop / $\mathrm{PC}$ and process it, Arduino gives commands/instructions to the stepper motor to work/rotate. From Arduino, it is not directly connected to the stepper motor but through the CNC shield module which is equipped with the driver module, where the driver module is here as an amplifier to drive the stepper motor. The stepper motor itself will rotate to move the $8 \mathrm{~mm}$ threaded bolt which will then move the $\mathrm{X}$, Y, and $\mathrm{Z}$ axes. The limit switch in Figure 3 is a barrier for each axis so that when the machine works it does not exceed the work area. While the power supply is used to supply the CNC shield module.

Arduino is a microcontroller that has become a unit on one board that only connects to the voltage source and Input / Output. Arduino requires a voltage of 5 volts DC for operation but in bord Arduino a jack for 12 volts DC is facilitated, where at 12 volts it will be lowered by the power supply circuit on the Arduino board to 5 volts DC. Arduino is a control that is easy to use and apply. Besides Arduino, an influential electronic component is the stepper motor. Where the stepper motor is one type of electromechanical drive that can move by converting electronic pulses into discrete mechanical movements. The movement of the stepper motor is based on the sequence of pulses given to the input, therefore if you want to move a stepper motor you must use a stepper motor controller that can generate periodic pulses.

The system on a 3-axis CNC router machine works with commands/instructions from a PC / laptop in the form of a G- 
Code code, to get the G-Code code the first step is to prepare a photo file with the format ".jpg or. with the aspire application and generate toolpaths in the form of $\mathrm{G}$ code or G-Code. The file with the G-Code format will be read/executed by the GRBL Controller application, the file will be displayed on the visualizer of the GRBL Controller application.

\section{RESULT AND ANALYSIS}

The results of this study include the conversion of photo files to G-code format, connecting the GRBL Controller application to a PC / laptop, working area parameters of a CNC machine, testing the movement of a 3 -axis $\mathrm{CNC}$ router machine, and engraving 3-dimensional photos.

\section{A. Testing Converting Photos to G-Code Format}

In the process of this research, photo files that can be executed with $\mathrm{CNC}$ router hardware are photos with G-Code format files. To get the G-Code format of the image you want to engrave with a $\mathrm{CNC}$ router, this research uses the Aspire application. Some of the steps taken to get the G-Code format file with the aspire application are as follows:

a. Open the aspire application and select the "Create a new file" menu to start a new project sheet.

b. After that, options will appear to set the work area, set the work area as needed.

c. The next step is to take the photo that will be converted by pressing the "Import Bitmap - for tracing" icon and select the photo file to be converted then press open.

d. After that, select the Modeling menu and press the icon "Create a component from selected or imported bitmap" to make the image into 3 dimensions as shown in Figure 3.

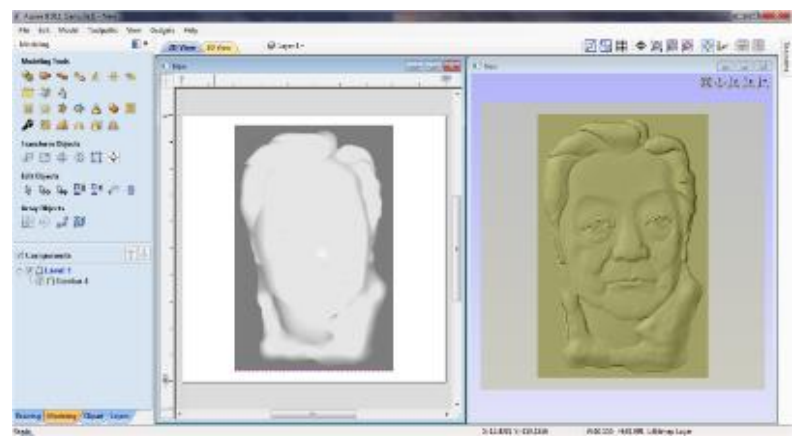

Fig. 3. 3 Dimensional Image Display

e. Press the icon "Change the properties of the selected components, including scale, tilt \& fade" to adjust the depth of the engraving that will be made and adjust it as needed.

f. Once set into engraving then go to creating toolpaths by pressing the "Switch to Toolpath commands" icon to display the toolpaths menu. Before that create a square area around the image.

g. For the initial step of making a face sketch carving is to create toolpaths with the 3D Roughing Toolpath, then the 3D Finishing Toolpath. To create a 3D Roughing Toolpath press the icon on the toolpaths menu.
The final step is to save the file by pressing the "Save Toolpath" icon and here set the Post Processor with the option "GRBL (mm) (*. Gcode) then press the Save Toolpath (s) button and select the folder where the file will be saved.

\section{B. Work Area Parameters Of CNC Machine}

Parameters that have been measured on the $\mathrm{X}$-axis of this 3 -axis CNC router machine have a length of $375 \mathrm{~mm}$. While the parameters that have been measured on the Y-axis of this 3 -axis CNC router machine have a length of $335 \mathrm{~mm}$. And the parameters measured on the $\mathrm{Z}$-axis of this 3 -axis $\mathrm{CNC}$ router machine have a length/height of $135 \mathrm{~mm}$.

Meanwhile, the overall dimensions of the CNC machine are $720 \mathrm{~mm}$ long, $650 \mathrm{~mm}$ wide, and $600 \mathrm{~mm}$ high. This machine has two power supplies, the first power supply has an output voltage value of 12 volts DC with a current of $14 \mathrm{~A}$ which is used to supply the control module, while the second power supply has an output voltage value between $0-110$ volts DC which can be adjusted by a potentiometer and is used for supply the spindle motor. For more details, see Figure 4.

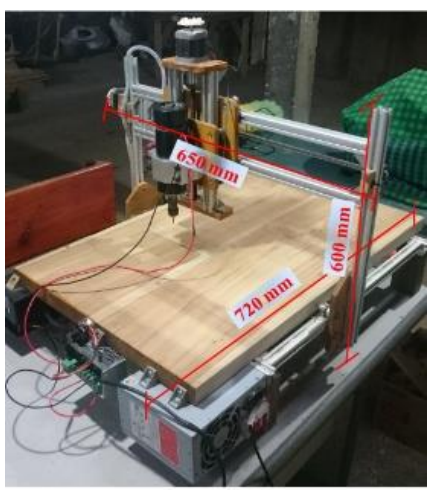

Fig. 4. Overall View of 3-Axis CNC Router Machine

\section{3 Dimensional Photo Measurement Results}

This research focuses on the influence or percentage of stretch used in the roughing and finishing processes. The process of roughing is the initial process in forming the basic pattern of an image, while finishing is the final process in sharpening the details of the image. In this study, three differences in the percentage of stretch were used both for the roughing and finishing stages. The stretch test is carried out to determine the results of the resulting engraved images and the completion time of one image engraving. The test is carried out in three stages, where the first test is the use of $40 \%$ roughing stretch and $15 \%$ finishing looseness which can be seen in Table 1.Testing using the same $40 \%$ percentage of roughing and finishing stretches can be seen in Table 2. And the last test uses The percentage of roughing and finishing stretches is the same as $15 \%$ can be seen in Table 3. The media used is from three different types of wood, namely, Dutch teak, ordinary teak, and mahogany. From each type of wood used, in this study the size of the wood media used was $90 \mathrm{~mm} \times 90 \mathrm{~mm}$. With the drill bit used in the roughing process, the size is $3 \mathrm{~mm}$, and the tool in the finishing process uses the size of $1.5 \mathrm{~mm}$, with the resulting image thickness is $5 \mathrm{~mm}$. 
Table 1.The results of the engraving process with $40 \%$ stretching and $15 \%$ finishing

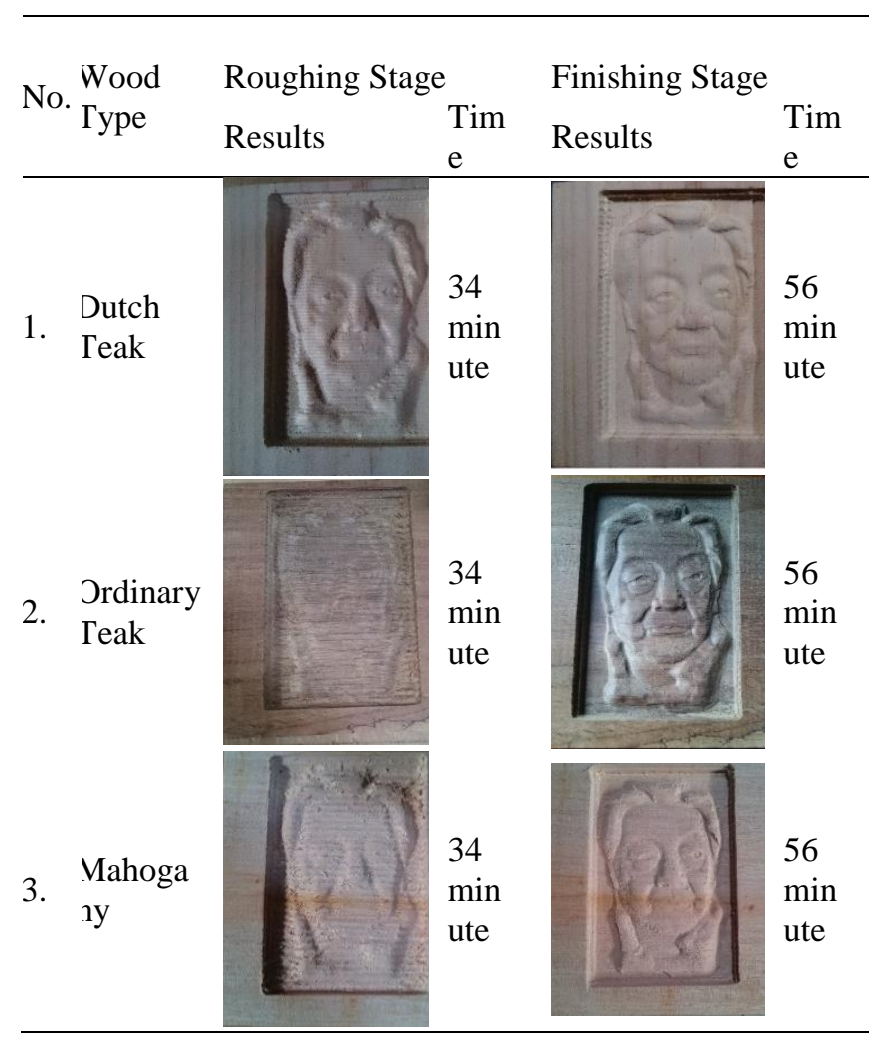

Table 2.The results of the engraving process with $40 \%$ stretching and $40 \%$ finishing

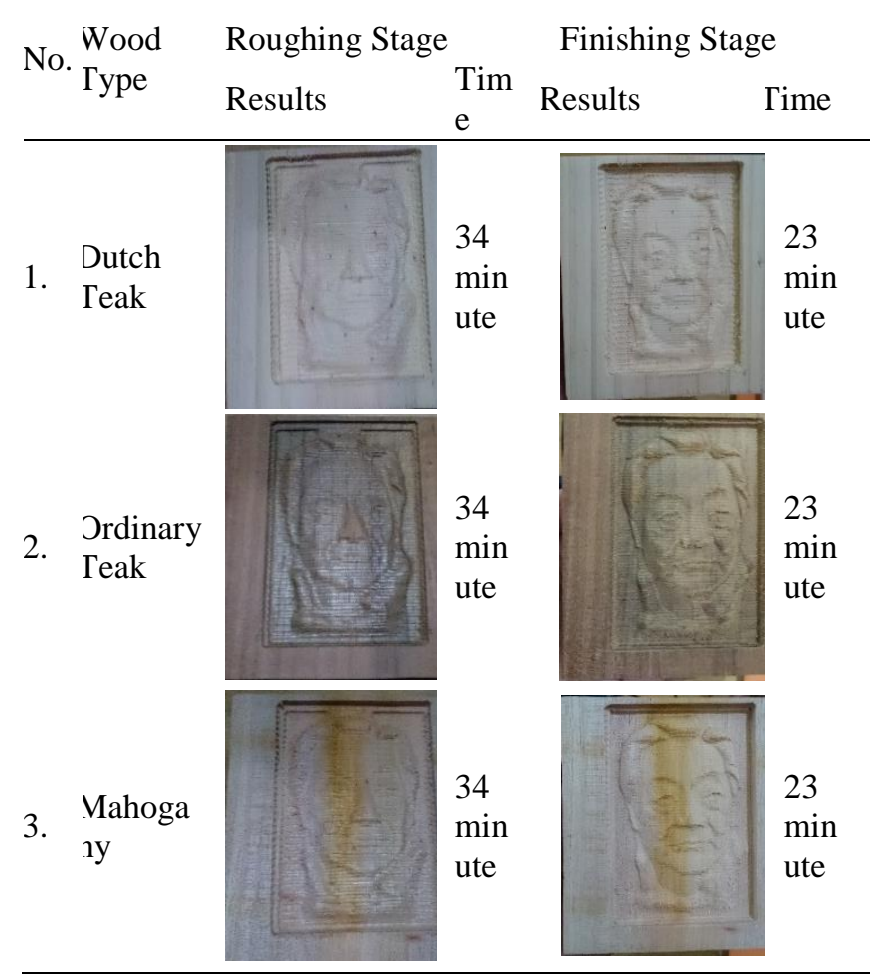

Table 3.Results of the Engraving Process with 15\% Roughing and $15 \%$ Finishing

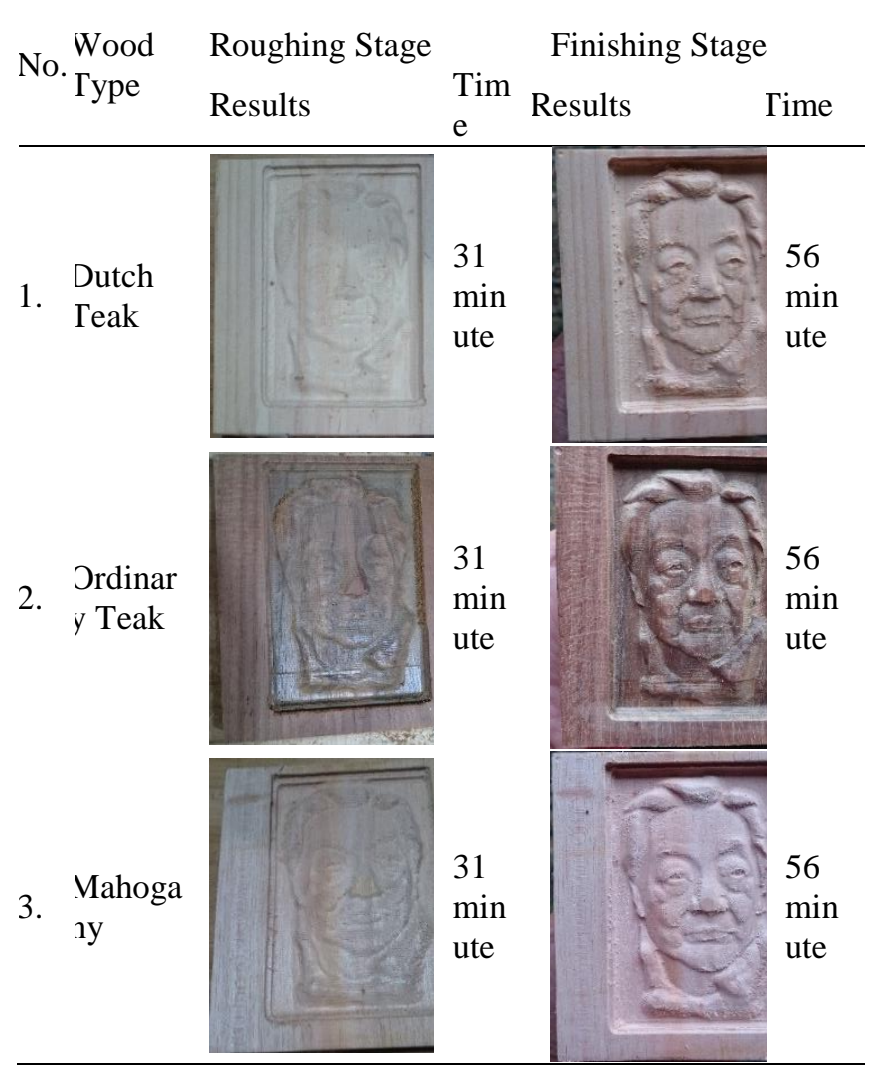

From the three studies that have been done, it can be seen that the percentage of stretch affects the carving results. In the roughing stage, the greater the percentage level of the gap in the given review, then the results are obtained for the formation of the basic pattern or initial pattern of the resulting review line more visible. The resulting image in the roughing process looks coarser for a large percentage of stretching. But the smaller the percentage level of roughing stretch that is given, the resulting image will look smoother lines. For the finishing process, it is a step taken to smooth the pattern that has been formed in the roughing process. In the finishing process by giving a $40 \%$ stretch percentage, the result is that the final image fibers are not smooth, more visible rough lines are still visible. Meanwhile, for giving a $15 \%$ gap in the finishing process, the final result is that the carving pattern looks smooth without the appearance of rough lines. The percentage gap also affects the time it takes for the system to complete an engraved design. The greater the gap given, the faster the time required for completion but the results obtained are not optimal. Likewise, the opposite condition, where the level of the gap given is small, then the required completion time is longer but the carvings are very fine without visible rough line fibers. With a long time consumption, this system still has shortcomings, in terms of the efficiency of energy consumption used

\section{CONCLUSION}

From the research that has been done, the results show that:

a) To get an image file in the form of G-Code format, the image conversion must be done using the Aspire application first. 
b) The results of the 3-dimensional facial photo engraving in the roughing stage have a striped image construction, while the finishing stage has a smooth image construction with a longer time lag compared to the roughing stage.

c) The use of a percentage of stretch in the roughing and finishing process has an impact on the smoothness of the carving, the sharpness of the image, the length of time to finish the carving, and the power consumption.

\section{REFERENCES}

[1] D. Aslan and Y. Altintas, "Prediction of Cutting Forces in Five-Axis Milling Using Feed Drive Current Measurements," IEEE/ASME Trans. Mechatronics, vol. 23, no. 2, pp. 833-844, Apr. 2018.

[2] I. Takeuchi and S. Katsura, "Interpolation of a Clothoid Curve Based on Iterative True-Value Prediction Considering the Discretization Error,” IEEE Trans. Ind. Informatics, vol. 14, no. 11, pp. 5156-5166, Nov. 2018.

[3] K. Zhou, J. Ding, C. Zhou, and W. Wu, "\$W\$ -Band Dual-Band QuasiElliptical Waveguide Filter With Flexibly Allocated Frequency and Bandwidth Ratios," IEEE Microw. Wirel. Components Lett., vol. 28, no. 3, pp. 206-208, Mar. 2018.

[4] K. Verma and R. M. Belokar, "Experimental investigations of ball screws over static and accelerating torque-based lead factor in CNC machining centre," J. Eng., vol. 2018, no. 1, pp. 17-21, Jan. 2018.

[5] T.-C. Lu, S.-L. Chen, and E. C.-Y. Yang, "Near Time-Optimal $<$ italic $>S</$ italic $>$-Curve Velocity Planning for Multiple Line Segments Under Axis Constraints," IEEE Trans. Ind. Electron., vol. 65, no. 12, pp. 9582-9592, Dec. 2018.

[6] R. Shi, Y. Lou, X. Zhang, and J. Li, "A Novel Task Coordinate Frame Reduced- Dimension 3-D Contouring Control," IEEE Trans. Autom. Sci. Eng., vol. 15, no. 4, pp. 1852-1863, Oct. 2018.

[7] J. Feng et al., "Fabrication of a $0.346-\mathrm{THz}$ BWO for Plasma Diagnostics," IEEE Trans. Electron Devices, vol. 65, no. 6, pp. 2156 2163, Jun. 2018.

[8] M. Hanifzadegan and R. Nagamune, "Contouring Control of CNC Machine Tools Based on Linear Parameter-Varying Controllers," IEEE/ASME Trans. Mechatronics, vol. 21, no. 5, pp. 2522-2530, Oct. 2016.

[9] J. Ding, D. Liu, S. Shi, and W. Wu, "W-band quasi-elliptical waveguide filter with cross-coupling and source-load coupling," Electron. Lett., vol. 52, no. 23, pp. 1960-1961, Nov. 2016.

[10] W. Zhang, Y. Zou, T. Lin, F. S. Chau, and G. Zhou, "Development of Miniature Camera Module Integrated With Solid Tunable Lens Driven by MEMS-Thermal Actuator,” J. Microelectromechanical Syst., vol. 26, no. 1, pp. 84-94, Feb. 2017.

[11] X. Shang, H. Yang, D. Glynn, and M. J. Lancaster, "Submillimeterwave waveguide filters fabricated by SU-8 process and laser micromachining," IET Microwaves, Antennas Propag., vol. 11, no. 14, pp. 2027-2034, Nov. 2017.

[12] M. A. Al-Tarifi and D. S. Filipovic, "On the design and fabrication of W-band stabilised-pattern dual-polarised horn antennas with DMLS and CNC," IET Microwaves, Antennas Propag., vol. 11, no. 14, pp. 1930-1935, Nov. 2017.

[13] H. Yang et al., "WR-3 Waveguide Bandpass Filters Fabricated Using High Precision CNC Machining and SU-8 Photoresist Technology," IEEE Trans. Terahertz Sci. Technol., vol. 8, no. 1, pp. 100-107, Jan. 2018.

[14] C. R. Donaldson, L. Zhang, M. Beardsley, M. Harris, P. G. Huggard, and W. He, "CNC Machined Helically Corrugated Interaction Region for a THz Gyrotron Traveling Wave Amplifier," IEEE Trans. Terahertz Sci. Technol., vol. 8, no. 1, pp. 85-89, Jan. 2018.

[15] A. Baig et al., "Performance of a Nano-CNC Machined 220-GHz Traveling Wave Tube Amplifier," IEEE Trans. Electron Devices, vol. 64, no. 5, pp. 2390-2397, May 2017.

[16] C.-S. Chen and Y. T. A. Sun, "Intelligent Computer-aided Process Planning of Multi-axis CNC Tapping Machine," IEEE Access, vol. 5, no. Ic, pp. 2913-2920, 2017

[17] X. Shang, M. Lancaster, and Y.-L. Dong, "W-band waveguide filter based on large TM120 resonators to ease CNC milling," Electron. Lett., vol. 53, no. 7, pp. 488-490, Mar. 2017.

[18] K. Zhu and Y. Zhang, "A Cyber-Physical Production System Framework of Smart CNC Machining Monitoring System," IEEE/ASME Trans. Mechatronics, vol. 23, no. 6, pp. 2579-2586, Dec. 2018.

[19] M. Ferrando-Rocher, J. I. Herranz-Herruzo, A. Valero-Nogueira, and B. Bernardo-Clemente, "Performance Assessment of Gap-Waveguide Array Antennas: CNC Milling Versus Three-Dimensional Printing," IEEE Antennas Wirel. Propag. Lett., vol. 17, no. 11, pp. 2056-2060, Nov. 2018.

[20] I. Iglesias, J. E. Ares, C. Gonzalez-Gaya, F. Morales, and V. F. Rosales, "Predictive Methodology for Dimensional Path Precision in Robotic Machining Operations," IEEE Access, vol. 6, pp. 49217-49223, 2018.

[21] X. Tian, L. Jiao, Z. Gan, C. Wang, and X. Zheng, "ConsistencyConstrained Nonnegative Coding for Tracking," IEEE Trans. Circuits Syst. Video Technol., vol. 27, no. 4, pp. 880-891, Apr. 2017.

[22] A. D. Vieira, E. A. P. Santos, M. H. de Queiroz, A. B. Leal, A. D. de Paula Neto, and J. E. R. Cury, "A Method for PLC Implementation of Supervisory Control of Discrete Event Systems," IEEE Trans. Control Syst. Technol., vol. 25, no. 1, pp. 175-191, Jan. 2017.

[23] N. de Oliveria Pacheco and J. de Oliveira Pacheco, "Implementation Supervisory Control Ladder Language for a Manufacturing Cell," IEEE Lat. Am. Trans., vol. 15, no. 2, pp. 219-224, Feb. 2017.

[24] Y. Chen and L. Li, "Smooth Geodesic Interpolation for Five-Axis Machine Tools," IEEE/ASME Trans. Mechatronics, vol. 21, no. 3, pp. 1592-1603, Jun. 2016.

[25] B. Zhu, S. Wang, and Y. Liu, "A Convolutional Network Coding Oriented Four-Stage Contention Protocol for All-to-All Broadcasting Networks," Chinese J. Electron., vol. 25, no. 1, pp. 192-198, Jan. 2016.

[26] M. Corapsiz and K. Erenturk, "Trajectory Tracking Control and Contouring Performance of Three Dimensional CNC," IEEE Trans. Ind. Electron., vol. 63, no. 4, pp. 1-1, 2016.

[27] W. Choi, I. Lee, and E. Choi, "Design and Fabrication of a $300 \mathrm{GHz}$ Modified Sine Waveguide Traveling-Wave Tube Using a Nanocomputer Numerical Control Machine," IEEE Trans. Electron Devices, vol. 64, no. 7, pp. 2955-2962, 2017.

[28] G. Chattopadhyay, T. Reck, C. Lee, and C. Jung-Kubiak, "Micromachined Packaging for Terahertz Systems," Proc. IEEE, vol. 105, no. 6, pp. 1139-1150, Jun. 2017.

[29] N. de Oliveira Pacheco, "Use neutral data interfaces for Numerical Controllers Computerized," IEEE Lat. Am. Trans., vol. 15, no. 6, pp. 1212-1218, Jun. 2017.

[30] Z. Zhou, J. Hu, Q. Liu, P. Lou, J. Yan, and W. Li, "Fog computingbased cyber-physical machine tool system," IEEE Access, vol. 6, pp. 44580-44590, 2018

[31] E. Natarajan, V. Kaviarasan, W. H. Lim, S. S. Tiang, and T. H. Tan, "Enhanced Multi-Objective Teaching-Learning-Based Optimization for Machining of Delrin," IEEE Access, vol. 6, pp. 51528-51546, 2018.

[32] I. Afifi, M. M. M. Ali, and M. Ali, "Analysis and Design of a Wideband Coaxial Transition to Metal and Printed Ridge Gap Waveguide," IEEE Access, vol. 6, pp. 70698-70706, 2018. 